\title{
LMO4 is an Essential Cofactor in the Snail2-Mediated Epithelial-to-Mesenchymal Transition of Neuroblastoma and Neural Crest Cells
}

\author{
Tiago Ferronha, ${ }^{1 \star}$ M. Angeles Rabadán, ${ }^{1 \star}$ Estel Gil-Guiñon, ${ }^{2 \star}$ Gwenvael Le Dréau, ${ }^{1}$ Carmen de Torres, ${ }^{2}$ \\ and Elisa Martí ${ }^{1}$ \\ ${ }^{1}$ Instituto de Biología Molecular de Barcelona, Consejo Superior de Investigaciones Científicas, Parc Científic de Barcelona, Barcelona 08028, Spain, and \\ ${ }^{2}$ Developmental Tumor Biology Laboratory, Hospital Sant Joan de Déu, Fundació Sant Joan de Déu, 08950 Barcelona, Spain
}

Neuroblastoma is an embryonic tumor derived from cells of the neural crest. Taking advantage of a newly developed neural crest lineage tracer and based on the hypothesis that the molecular mechanisms that mediate neural crest delamination are also likely to be involved in the spread of neuroblastoma, we were able to identify genes that are active both in neural crest development and neuroblastoma tumor formation. A subsequent search of the neuroblastoma gene server for human orthologues of genes differentially expressed in the chick embryo neural crest screen retrieved the LIM domain only protein 4 (LMO4), which was expressed in both cell types analyzed. Functional experiments in these two model systems revealed that LM04 activity is required for neuroblastoma cell invasion and neural crest delamination. Moreover, we identified LMO4 as an essential cofactor in Snail2-mediated cadherin repression and in the epithelial-tomesenchymal transition of both neural crest and neuroblastoma cells. Together, our results suggest that the association of high levels of LMO4 with aggressive neuroblastomas is dependent on LMO4 regulation of cadherin expression and hence, tumor invasiveness.

\section{Introduction}

Neuroblastoma (NB) is a neurological tumor that arises from neural crest (NC) cells and it is the most common extracranial tumor in children (Brodeur, 2003; Maris et al., 2007). NB represents a very heterogeneous group of tumors in terms of their biological, genetic, and morphological characteristics. Clinically, these tumors may develop distinctly, ranging from spontaneous remission by differentiation and/or apoptosis (resembling normal NC behavior), to aggressive metastatic disease with low overall survival rates. The neuroectodermal origin of NB suggests that these tumors can spread from their primary site using mechanisms similar to those involved in the delamination and dispersion of the embryonic NC, and that gene(s) implicated in NC cell migration may also be involved in the acquisition of the invasive

\footnotetext{
Received Sept. 20, 2012; revised 0ct. 27, 2012; accepted Dec. 4, 2012.

Author contributions: T.F., M.A.R., E.G.-G., G.L.D., and E.M. designed research; T.F., M.A.R., E.G.-G., G.L.D., and C.D.T. performed research; T.F., M.A.R., E.G.-G., G.L.D., and E.M. contributed unpublished reagents/analytic tools; T.F., M.A.R., E.G.-G., G.L.D., C.d.T., and E.M. analyzed data; E.M. wrote the paper.

Work in E.M.'s laboratory was supported by Grants BFU2010-18959 and CSD2007-00008. T.F. is a recipient of Predoctoral Fellowship Grant BES-2008-003977. Work in C.d.T.'s laboratory was supported by Cellex Foundation, Caja Navarra, Ass P. Ugarte, and J. M. Buesa (Spanish Group for Sarcoma Research). We are grateful to the members of the Martí lab and to Dr Angela Nieto for helpful discussions, as well as to Susana Usieto for invaluable technical assistance. For DNAs and antibodies, we thank Drs B. Andersen, A. Nieto, E. Battle, C. Birchmeier, M. Goulding, and S. Pons.

The authors declare no competing financial interests.

*T.F., M.A.R., and E.G.-G. contributed equally to this work.

Correspondence should be addressed to either Carmen de Torres, Developmental Tumour Biology Laboratory, Hospital Sant Joan de Déu, Fundació Sant Joan de Déu, Barcelona, Spain, E-mail: cdetorres@hsjdbcn.org; or Elisa Martí, Instituto de Biología Molecular de Barcelona, CSIC, Parc Científic de Barcelona, C/Baldiri i Reixac 20, Barcelona 08028, Spain, E-mail: emgbmb@ibmb.csic.es.

DOI:10.1523/JNEUROSCI.4511-12.2013

Copyright $\odot 2013$ the authors $\quad 0270-6474 / 13 / 332773-11 \$ 15.00 / 0$
}

NB phenotype (De Preter et al., 2006; Jiang et al., 2011). Thus, better understanding the biology of NC development may shed light on the basic mechanisms involved in NB progression and aid the search for directed therapies.

NC cells delaminate from the dorsal neural tube (NT) and migrate toward their destinations (Thiery et al., 2009). Before delamination, cells in the dorsal NT are specified as NC progenitors (Betancur et al., 2010; Theveneau and Mayor, 2012). Snail transcription factors are expressed in the premigratory $\mathrm{NC}$ of all vertebrate species analyzed, and they are particularly crucial for NC development. Moreover, their activity is required for the epithelial-to-mesenchymal transition (EMT) and for delamination of these cells from the NT. EMT converts epithelial cells into migratory and invasive mesenchymal cells, and it has also been implicated in the metastatic cascade of tumors (Thiery et al., 2009).

Given the similarities in the behavior of NC cells and NB, we sought to identify genes involved in both NC development and NB tumor formation. Taking advantage of a newly developed NC lineage tracer, we performed a genome-wide screen of the genes expressed in the chick embryo. Searching the Neuroblastoma Gene Server for the human orthologues of genes differentially expressed in the NC screen, we retrieved the LIM domain only (LMO) protein 4. LMO4 encodes a transcriptional regulator that contains two LIM zinc-binding domains for protein-protein interactions, but lacks the DNA-binding or catalytic domains. LMO4 belongs to a protein subfamily encoded by four genes (LMO1-4), and its paralogues LMO1 and LMO3 are NB oncogenes (Aoyama et al., 2005; Isogai et al., 2011; Wang et al., 2011). In the developing mammalian spinal cord, LMO4 contributes to 
Table 1. Sequences of primers used for the generation of chick sh-LM04 shRNA

\begin{tabular}{|c|c|c|}
\hline$\overline{\text { Ref. }}$ & Oligo & Sequence \\
\hline \multirow[t]{2}{*}{ sh-LM04-a } & Fw Oligo & 5'-gatcCCCGCATGATCCTCTGCAGAAATTCAAGAGATTTCTGCAGAGGATCATGCttttta-3' \\
\hline & Re Oligo & 5'-agcttAAAAAGCATGATCCTCTGCAGAAATCTCTTGAATTTCTGCAGAGGATCATGCggg - 3' \\
\hline \multirow[t]{2}{*}{ sh-LM04-b } & Fw Oligo & 5'-gatcCCCGGAGATCGGTTTCACTACATTCAAGAGATGTAGTGAAACCGATCTCCttttta-3' \\
\hline & Re 0ligo & 5'-agcttAAAAAGGAGATCGGTTTCACTACATCTCTTGAATGTAGTGAAACCGATCTCCggg -3' \\
\hline \multirow[t]{2}{*}{ sh-LM04-c } & Fw Oligo & 5'-gatcCCCTGTCTATCATCTGAAGTGTTTCAAGAGAACACTTCAGATGATAGACAtttttggaaa-3' \\
\hline & Re 0ligo & 5'-agctttccaaaaaTGTCTATCATCTGAAGTGTTCTCTTGAAACACTTCAGATGATAGACAggg - 3' \\
\hline
\end{tabular}

Fw, Forward; Re, reverse.

Table 2. Sequences of primers used for the generation of human sh-LM04 shRNA

\begin{tabular}{lllll}
\hline Ref. & Clone ID & Clone name & Match position & Sequence \\
\hline sh-A & TRCN0000013240 & NM_006769.2-1156s1c1 & 1156 & 5'-CCGG-GATCGGTTTCACTACATCAAT-CTCGAG-ATTGATGTAGTGAAACCGATC-TTTTT-3' $^{\prime}$ \\
sh-B & TRCN0000013241 & NM_006769.2-1165s1c1 & 1165 & $5^{\prime}$-CCGG-CACTACATCAATGGCAGTTA-CTCGAG-TAAACTGCATTGATGTAGTG-TTTTT-3' \\
sh-C & TRCN0000013242 & NM_006769.2-999s1c1 & 999 & $5^{\prime}$-CCGG-CAGAAATGACTACATTAGGTT-CTCGAG-AACCTAATGTAGTCATTTCTG-TTTTT-3' \\
\hline
\end{tabular}

the segregation of neuronal subtypes (Lee et al., 2005; Joshi et al., 2009) and, in the Xenopus embryo, participates in the acquisition of NC identity (Ochoa et al., 2012). Here, we show that LMO4 is expressed in human NB cells and chick NC cells. Functional experiments in both models revealed that LMO4 activity is required for the invasiveness of NB cells and NC delamination. Furthermore, we show that LMO4 is an essential cofactor in Snail2mediated cadherin repression and EMT in NC and NB cells.

\section{Materials and Methods}

DNA constructs. The BMP reporter construct (BRE-tk-GFP) used here has been previously described (Le Dréau et al., 2012), as has the E-cadherin-luciferase reporter construct (Batlle et al., 2000). Human LMO4 (Lu et al., 2006) and chicken Snail2 (Morales et al., 2007) were subcloned into pCAGGS-ires-GFP or pCAGGS-ires-H2B-RFP.

To knockdown LMO4 in chick embryos, short RNA hairpin (shRNA)based expression vectors were generated (Tables 1). The knockdown of human LMO4 in neuroblastoma cell lines was achieved using shRNA plasmids from the RNAi Consortium (Sigma-Aldrich), (Table 2).

FACS and microarray analysis. DNA was microinjected into the embryonic NT and the embryos were then electroporated using an Intracel Dual Pulse TSS-100 electroporator. The NT was recovered $24 \mathrm{~h}$ after coelectroporation of the pBRE-tk-GFP reporter and the pCAGGS-ires$\mathrm{H} 2 \mathrm{~B}-\mathrm{RFP}$ construct, and a single-cell suspension was obtained following a 10-15 min Trypsin-EDTA digestion. GFP and RFP fluorescence was determined, cells were sorted by flow cytometry using a MoFlo flow cytometer (Dako), and total RNA was extracted using the standard Trizol (Promega) protocol.

cDNAs were synthesized and hybridized to the GeneChip Chicken Genome Array (Affymetrix). Bioconductor software was used to analyze the data, which were normalized using the "rma" algorithm to identify differentially expressed genes. The results were filtered using thresholds of $[\log 2 \mathrm{FC}]>0.5849$ and a $p<0.05$.

$R T-P C R$ and evaluation of RNAi efficiency by quantitative real-time$P C R$. The primers used for qPCR amplification of target genes were purchased from QuantiTec Primer Assays (Qiagen). PCR amplifications were assessed from pools of electroporated NT (15/pool) using two to three independent pools per experimental condition, $\mathrm{GFP}^{+}$cells were FACS sorted, and total RNA was extracted. The data represent the mean values \pm SEM.

Total RNA was isolated from neuroblastoma cell lines using the TRI Reagent (Sigma-Aldrich) and qPCR was performed on an ABI Prism 7000 Sequence Detection System using Q-PCR Taqman Gene Expression Assays (Applied Biosystems). The quantification of LMO4 (Hs00232488_m1) and E-cadherin mRNA (Hs 01023894_m1) transcripts was normalized to TATA box binding protein (Hs00427620_ms1) expression and to the cell line with the lowest amplification level (LAN1).
Immunohistochemistry and in situ hybridization. Embryos of either sex were fixed for $2-4 \mathrm{~h}$ at $4^{\circ} \mathrm{C}$ in $4 \%$ paraformaldehyde (PFA) in PBS and sections were immunostained following standard procedures with antibodies against: Islet1, Lmx1b, and Pax7 (Developmental Studies Hybridoma Bank); Id4 and ZO1 (Invitrogen); aPKC (Santa Cruz Biotechnology); HNK-1 and Laminin (Sigma); N-cadherin (Zymed); phospho-Histone-3 (Millipore); and cleaved caspase 3 (BD Biosciences). Cells were counted in images obtained from at least six different chick embryos for each experimental condition. The data are represented as the mean \pm SEM.

For in situ hybridization, embryos were fixed overnight at $4^{\circ} \mathrm{C}$ in $4 \%$ PFA in PB and then processed for whole-mount RNA in situ hybridization following standard procedures. The embryos were hybridized with probes against chick LMO4, FoxD3, Snail2, Sox9, and Sox10 (from the chicken EST project, UK-HGMP RC) and were postfixed in 4\% PFA. Vibratome sections were photographed on a Leica DMR microscope.

Luciferase reporter assay. Transcriptional activity assays of LMO4 and Snail2 were performed using the E-cadherin-luciferase reporter (Batlle et al., 2000). Embryos were electroporated with the indicated DNAs together with the firefly-luciferase vector and a renilla-luciferase reporter construct (Promega) for normalization, harvested at $24 \mathrm{~h}$ postelectroporation (hpe) and homogenized in passive lysis buffer. Firefly and renilla luciferase activity was measured using the Dual Luciferase Reporter Assay System (Promega). Data are represented as the mean \pm SEM from 8-12 embryos per experimental condition.

SH-SY5Y cells were transfected using X-treme 9 transfection reagent (Roche) with indicated DNAs, harvested $24 \mathrm{~h}$ after transfection, and the firefly and renilla luciferase activities were measured using the Dual Luciferase Reporter Assay System.

Neural crest explant culture and time-lapse analysis. Chick embryos were electroporated with the indicated DNAs and the NT was dissected out at 3 hpe. NT explants were cultured in DMEM-F12 (D6421; Sigma), $0.01 \%$ penicillin-streptomycin (Invitrogen), and $0.001 \%$ Myto $^{+}$(BD Bioscience). Time lapse analysis of $\mathrm{NC}$ cell migration was performed as previously described (Duband et al., 2009) using a Leica SP5 confocal microscope.

The data from the cell tracking assay was processed using ImageJ, whereby migratory cells were treated as particles centered on their own nuclei and tracked using the ImageJ Manual Tracking plug-in.

Cell lines. The LAN-1, SK-N-LP, and SK-N-JD cell lines were provided by Dr N. K. V. Cheung (Memorial Sloan Kettering Cancer Center, New York, NY), the LA1-5S line by Dr B. Spengler (Fordham University, New York, NY), and the SH-SY5Y cells by Dr V. J. Yuste (Institut de Neurociencies, Medicina, UAB, Spain). The SK-N-AS cell line was purchased from the European Collection of Cell Cultures (Wiltshire, UK).

Lentivirus production and lentivirus-mediated shRNA knockdown. Lentiviral virions expressing shLMO4 and control shRNA were produced by transient cotransfection of the HEK 293T packaging cell line with pCMV-VSV-G and the vectors containing the LMO4 shRNA (pLKO.1- 
LMO4; Sigma-Aldrich). Control lentivirus was produced using the pLKO.1 vector containing a scrambled nontargeting short-hairpin RNA sequence (Addgene).

SK-N-LP neuroblastoma cells were transduced with lentiviralcondictioned media and selected for 2 weeks in medium containing puromycin (Sigma-Aldrich) and puromycin-resistant cells were subsequently pooled.

SDS-PAGE and Western blotting. Electroporated chick NTs were recovered at 24 hpe, cleaned, and frozen. Protein was extracted using RIPA buffer and quantified by the Bradford method. These samples were examined in Western blots probed with antibodies against N-cadherin (Invitrogen) and b-tubulin (Millipore). Densitometric analysis was performed using Quantity One software (Bio-Rad).

Total cell lysates from shRNA-LMO4 NB (SK-N-LP) cell lines were harvested in hot lysis buffer, quantified by the Bio-Rad Protein Assay, and analyzed by Western blots using antibodies against cleaved caspase- 3 (Cell Signaling Technology) and GAPDH (Millipore). SH-SY5Y cells treated for $6 \mathrm{~h}$ with $1 \mu \mathrm{M}$ Staurosporine (Sigma) were used as a positive control.

Thymidine proliferation assay. NB SK-N-LP shLMO4 cells were cultured in complete medium for $48 \mathrm{~h}$ and then incubated for $4 \mathrm{~h}$ with ${ }^{3} \mathrm{H}$-thymidine (Amershan-Pharmacia Biotech). Cells were lysed with $0.04 \%$ SDS before processing the lysates for liquid scintillation counting (Optiphase 2; PerkinElmer Life Sciences) and measurements were performed with a WinSpectral 1414 liquid scintillation counter (Wallac).

In vitro wound-healing migration assay. SK-N-LP cells expressing shLMO4 were seeded into $60 \mathrm{~cm}$ plates (Corning) and grown to confluence. A single wound was then created in the cell monolayer and migration of the cells from the edge of the wound was analyzed in images taken every $3 \mathrm{~h}$. The area between the wound edges was measured at each time point using ImageJ software (as described previously by Dr Kees Straatman, Advanced Imaging Facilities, University of Leicester, Leicester, UK). The area immediately after creation of the wound was set as $100 \%$, and the relative change was calculated as a percentage of the initial area.

In vitro invasion assay. The membranes of the Transwell invasion assay inserts (Corning Costar) were coated with Matrigel (BD Biosciences) and hyaluronic acid. shLMO4-SK-N-LP cells were plated onto the upper chamber in RPMI 1640 medium supplemented with $0.1 \%$ fetal bovine serum and complete medium was added to the lower chamber. After $24 \mathrm{~h}$ incubation, cells on the upper side of the membrane were removed and those that had migrated into the receiver well were trypsinized and stained with propidium iodide (Sigma). Analyses were performed with an Epics XL flow cytometer (Coulter) using Flowcheck (Beckman Coulter) as an internal standard for cell counting. Experiments were performed in triplicate and the data is represented as an index of invasion relative to the pLKO control.

Statistics. Statistical analysis was performed using Statview software, analyzing the data using a Student's $t$ test, except for the increasing concentrations of Snail2, the effects of which were analyzed by ANOVA followed by a Student-Newman-Keuls test. A heatmap graph was generated using R software (The R Project for Statistical Computing). Quantitative data are presented as the mean \pm SEM.

\section{Results}

\section{LMO4 is common to neural crest and neuroblastoma cells}

To identify elements of the NC cell transcriptome, we used the BMP-Responsive Element (BRE-tk-GFP) to drive stable GFP expression in the dorsal spinal cord (Fig. 1A) (Le Dréau et al., 2012). Chick embryos [Hamilton-Hamburger $(\mathrm{HH})$ stage 10] were coelectroporated with BRE-tk-GFP and pCAGGS-ires-H2B-RFP, which drives RFP expression along the entire dorsal-ventral axis of the NT. The embryos were allowed to develop for $24 \mathrm{~h}$ and transfected cells expressing GFP or RFP were purified by FACS. Total RNA was extracted from these cells and gene expression was assayed in the two cell populations using the Affymetrix GeneChip. Several genes known to be expressed in the dorsal NT were enriched in the GFP-expressing cell population. Accord- ingly, we identified a total of 413 genes that were differentially expressed by the two cell populations (Fig. 1B).

We next searched the Neuroblastoma Gene Server to identify the human orthologues of these 413 genes, retrieving a total of 80 genes common to NC cells and NB tumor cells (Fig. 1C). Among them, LMO4 was of particular interest as high levels of LMO4 have been reported in aggressive stage IV NB (Yamanaka et al., 2002). Furthermore, two different NB cell lines strongly express LMO4 in transcriptome profiles associated with an aggressive phenotype (Schramm et al., 2005; Schulte et al., 2005). Since the role of this protein in NB remains unknown, we analyzed the expression of LMO4 in a panel of human NB cell lines. Gene expression analysis of these NB cell lines serve to classify them as neuroblastic $N$-type (LAN-1 and SH-SY5Y), intermediate I-type (SK-N-JD and SK-NLP), and Schwannian/glial S-type (SK-N-AS and LA1-5S) (Fig. 1D). LMO4 was expressed more strongly in the aggressive I-type cell lines (Fig. 1E). Thus, we selected the SK-N-LP cell line for further functional analysis of LMO4.

\section{Neuroblastoma cell invasiveness is dependent on LMO4}

To investigate the function of LMO4 in NB, we knocked down LMO4 expression using a shRNA containing lentivirus (Fig. 2A). In contrast to breast cancer cells in which low levels of LMO4 expression is associated with reduced proliferation (Sum et al., 2005), reduced LMO4 expression had no effect on the proliferation or apoptosis of NB cells (Fig. $2 B, C$ ). Hence, the activity of LMO4 does not appear to be essential for NB tumor cell viability.

When we next analyzed the migratory properties of NB cells in a wound-healing assay, the impaired capacity of NB cells to close the wound reflected the extent of LMO4 expression, linking LMO4 activity with cell motility (Fig. $2 D-F$ ). On the basis of these results, we examined the invasive capacity of NB cells in an extracellular matrix (Matrigel), an assay that provides a correlate of in vivo metastatic potential. These confirmed that the invasive capacity of NB cells is dependent on the levels of LMO4 expression (Fig. 2G). Together, these findings strongly suggest that LMO4 regulates the migratory and invasive behavior of NB cells, without affecting their viability. As such, and in the search for a common mechanism controlling NB and NC cell behavior, we next investigated the role of LMO4 in neural development in vivo.

\section{LMO4 is expressed by the neural crest}

LMO4 is necessary for the development of the mammalian nervous system as mutant mouse embryos lacking LMO4 exhibit exencephaly and die (Hahm et al., 2004; Tse et al., 2004; Lee et al., 2005). LMO4 is expressed in the neural plate and in NC cells of the Xenopus embryo (Ochoa et al., 2012) and, since we identified LMO4 when attempting to study the chick NC transcriptome, it appears likely that LMO4 function is conserved in early neural development across vertebrates.

To validate the results of our screening, we analyzed the expression of LMO4 in chick embryos, demonstrating that it is expressed in the cranial NC at the 10-somite stage (Fig. $3 A$ ). In the anterior NT, LMO4 expression is restricted to the dorsalmost NT, containing premigratory NC (Fig. $3 A$ ), whereas caudally, it is widely expressed in the open neural plate (Fig. $3 A i v, A v)$. After NT closure and the onset of NC migration, LMO4 expression is restricted to the dorsal NT, the migratory NC, and the trunk NC derivatives (Fig. $3 B$ and data not shown).

The early expression of LMO4 in the chick embryo suggests it fulfils a role in the specification and/or maintenance of NC identity. To test this possibility, we overexpressed LMO4 in the NT of chick embryos and analyzed the expression of components of the 


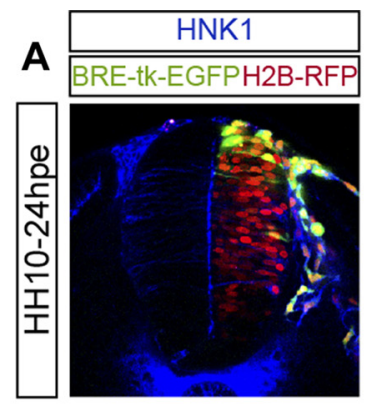

C
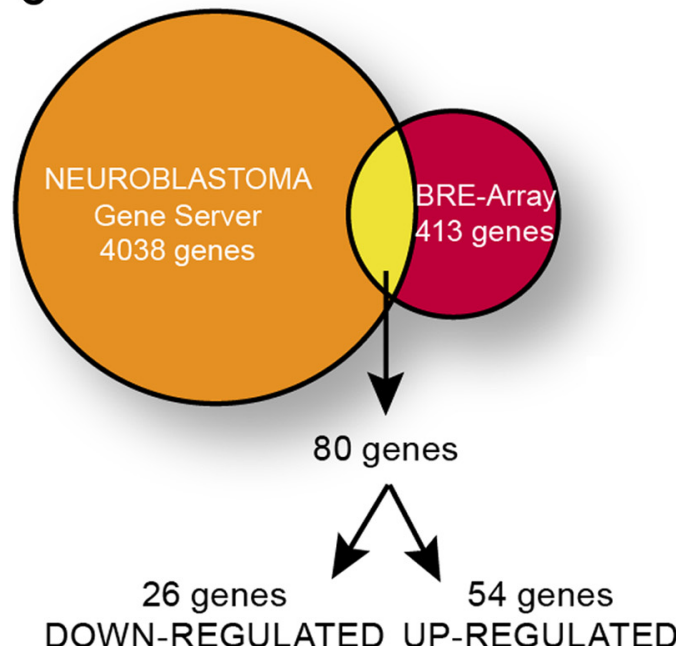

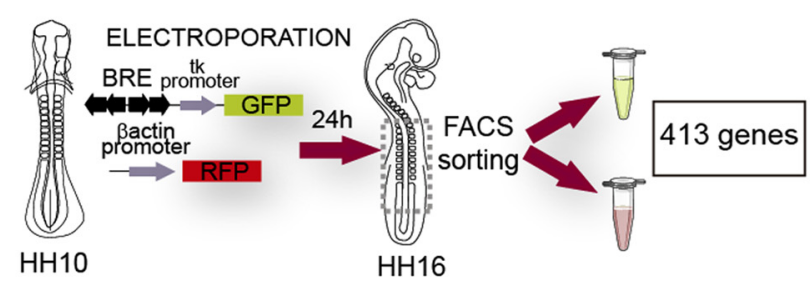

D

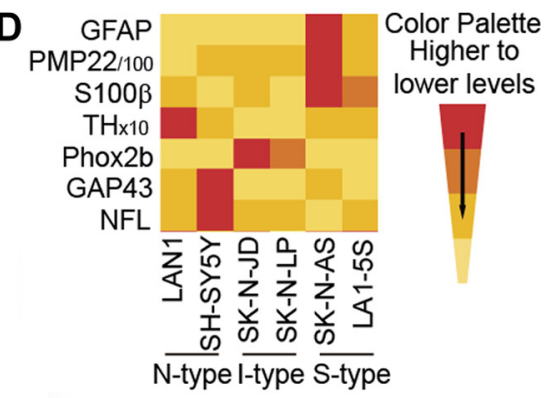

$\mathbf{E}$

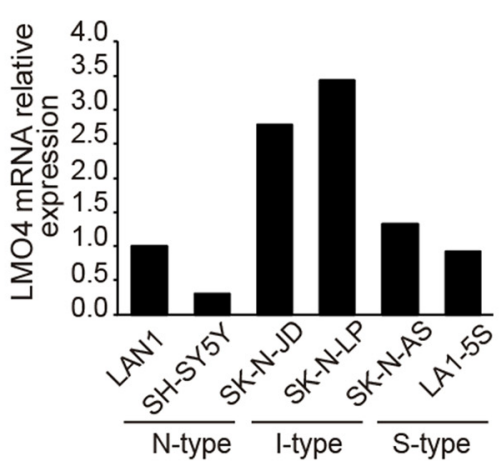

Figure 1. Identification of $L M 04$ as a gene expressed by both neural crest and neuroblastoma cells. $A$, Representative image showing coelectroporation with BRE-tk-GFP (green) and a control plasmid expressing pCAGGS-H2B-RFP (red). GFP-expressing cells were restricted to the dorsal NT and NC cells, which also express the NC marker HNK1 (blue). B, Schematic representation of the FACS sorting and transcriptome screening for NC genes. C, Schematic representation of the analysis of the BRE-array data, which was compared with Neuroblastoma Gene Server data to retrieve LM04 as a common hit. D, Molecular characterization of neuroblastoma cell lines. While the expression of Phox2b identifies these cells as neuroblastomas, the relative expression of glial markers (GFAP, PMP22, and S100 $\beta$ ) and neural markers (GAP43 and neurofilaments) allows for the subgroup association as neural (N-type), glial (S-type), or intermediate (I-type). E, LM04 expression measured by RT-qPCR in neuroblastoma cell lines; results are expressed relative to those of LAN1 cells.

NC gene regulatory network (del Barrio and Nieto, 2002; Cheung et al., 2005; Betancur et al., 2010). In contrast to the findings in Xenopus embryos (Ochoa et al., 2012), LMO4 activity was insufficient to ectopically activate NC-specific genes at this developmental stage in the chick (Fig. 3C).

LMO4 controls the delamination of neural crest cells from the dorsal NT

Based on the control exerted by LMO4 on the migratory and invasive behavior of NB cells, we investigated whether gain or loss of LMO4 function in chick embryos in vivo affected NC migration. Knockdown of endogenous LMO4 was achieved in the developing NT by electroporating short-hairpin RNA. This approach produced a significant reduction in RNA levels $\sim 36$ hpe, but it did not affect cell proliferation or survival in the NT (Fig. 4A-C).

LMO4 knockdown blocked NC migration in a cell autonomous manner. Indeed, when compared with the controls, the loss of LMO4 led to the retention of cells within the NT at 24 hpe (Fig. $4 D$ ), and an $\sim 80 \%$ loss of migratory NC cells at 48 hpe (Fig. $5 A, B)$. Moreover, the number of GFP-labeled cells was reduced in the trunk NC to a similar extent in all derivatives [dorsal root ganglia (DRG), sympathetic ganglia, and melanocytes; Fig. 5)]. Impaired delamination was rescued by the overexpression of human LMO4, which reverted the effect of the shRNA, demonstrating the specificity of this phenotype (Fig. 5C-E). Furthermore, LMO4 knockdown resulted in a $\sim 20 \%$ reduction of total DRG cells (data not shown).

Overexpressing LMO4 had no effect on proliferation, either within the NT or in migratory cells (Fig. $4 C$ and data not shown) but increased NC migration 24 hpe (Fig. 4D). After 48 hpe, it produced a $\sim 30 \%$ increase in the number of GFP-labeled migratory $\mathrm{NC}$ cells when compared with the control embryos (Fig. 5B). LMO4 expressing cells were not preferentially located to distinct $\mathrm{NC}$ derivatives, indicating that LMO4 promotes the migration of all trunk $\mathrm{NC}$ and suggesting a role for LMO4 in the early stages of $\mathrm{NC}$ migration.

Since LMO4 appears to influence NC migration, we analyzed $\mathrm{NC}$ cell movement in an explant assay. When cell movement was analyzed by time-lapse microscopy, a similar number of NC left NT explants obtained from control and LMO4-GFP electroporated embryos (Fig. 6), without exhibiting directional migration 
A
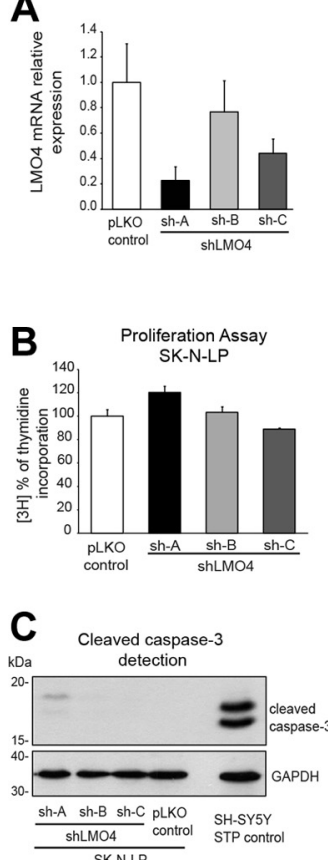

D
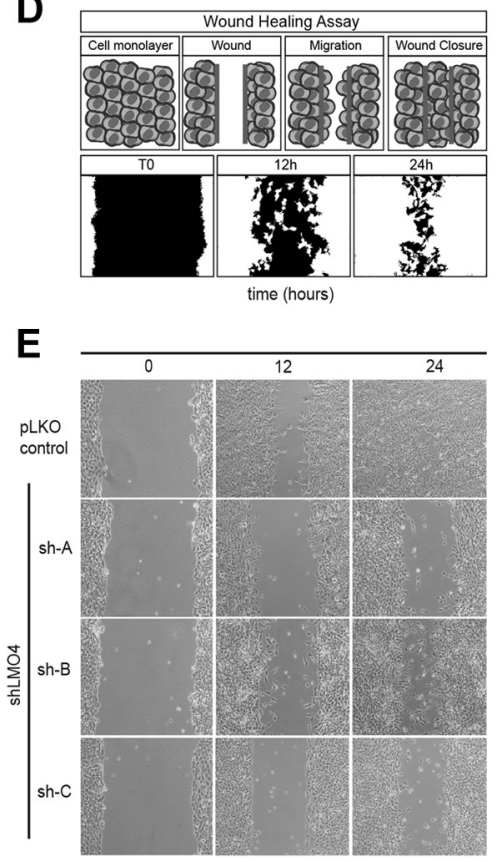

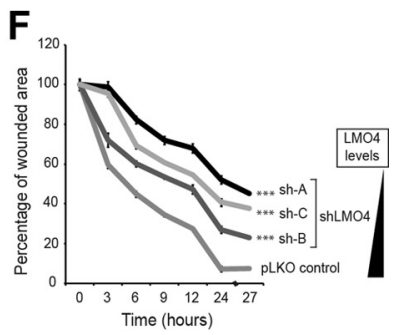

G
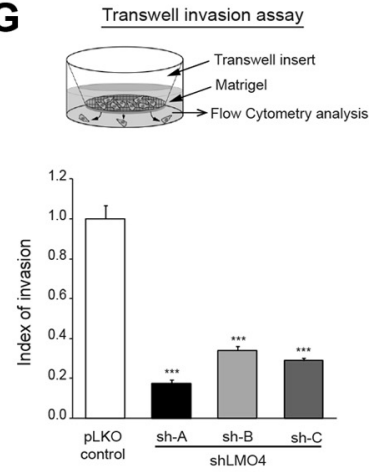

Figure 2. Neuroblastoma cell invasiveness is dependent on LM04. A, Efficiency of LM04 gene silencing using shRNA in SK-N-LP cells, as measured by RT-qPCR. LM04 mRNA expression was calculated relative to that of scrambled shRNA (pLKO control; error bars indicate the SD). B, LMO4 expression is not required for SK-N-LP cell proliferation. DNA synthesis was determined by measuring ${ }^{3} \mathrm{H}$-thymidine incorporation in cells expressing the shRNAs indicated during the last $4 \mathrm{~h}$ of a $48 \mathrm{~h}$ culture. Data represent the means ( \pm SEM) of four independent cultures. $\mathrm{C}$, Downregulation of LM04 in SK-N-LP cells does not significantly increase apoptotic caspase activation. Total cell extracts from SK-N-LP cells expressing the indicated shRNAs were analyzed in Western blots probed with cleaved caspase-3 antibody. GAPDH was used as a loading control. $\mathbf{D}-\boldsymbol{F}$, LM04 activity is required for NB cell migration. $\boldsymbol{D}$, Schematic representation of the wound healing assay and its quantification. Measurement of the wounded areas was performed using ImageJ by enhancing the contrast between cells and the wound, thereby permitting automatic measurement of the area. $\boldsymbol{E}$, Representative images of cell migration in a wound-healing assay using SK-N-LP cells expressing the indicated shRNAs. $\boldsymbol{F}$, Changes in wound area were calculated as a percentage (mean \pm SEM) of the initial wound area $\left({ }^{* * *} p<0.001\right)$. G, NB cell invasiveness is dependent on LMO4 activity. Schematic representation of the insert containing the Matrigel-coated porous membrane on which NB cells were seeded. After 24 hours, the fraction of cells that migrated through the matrix was determined by flow cytometry. The data represent the index of invasion relative to $\mathrm{pLK} 0$ control $\left.{ }^{* * *} p<0.001\right)$. Cell lines with lower levels of LM04 exhibited reduced invasive properties.

and showing similar speed of movement (Fig. 6). However, cells overexpressing LMO4 covered the first $50 \mu \mathrm{m}$ in $\sim 70 \mathrm{~min}$, while control cells required $100 \mathrm{~min}$ to cover a similar distance (Fig. 6), suggesting precocious delamination from the explants.

Together, these data indicate that LMO4 is not sufficient to trigger the genetic program underlying NC production, nor does it regulate proliferation or survival of NB or NC cells. However, LMO4 does appear to play a conserved role in NB invasiveness and the delamination of $\mathrm{NC}$ cells, prompting us to investigate the mechanisms underlying such effects.

\section{LMO4 is a necessary cofactor of Snail2 when mediating EMT in neural crest cells}

Delamination of the NC from the NT is a bona fide example of full EMT, and transcription factors from the Snail family are sufficient to trigger a full EMT program in the NT (Nieto, 2011). However, in our in vivo knockdown experiments, endogenous Snail2 was insufficient to trigger NC delamination in the absence of LMO4 (Fig. 5A). In addition, the increase of $\mathrm{NC}$ migration produced by overexpression of Snail2 is significantly reduced in the absence of LMO4 (Fig. 7A,B). Interestingly, we showed that increased dosage of Snail2 can overcome impaired NC migration (Fig. 7C,D). Hence, a functional interaction appears to exist between LMO4 and Snail2, which is consistent with the direct protein interaction between the LIMdomains of LMO4 and the $N$ terminus domain of Snail1 and Snail2 recently described (Ochoa et al., 2012).

To further study the role of LMO4 in delamination, we analyzed the integrity of the basal lamina. Staining with laminin revealed that the ectopic disruptions of the basal lamina caused by Snail2 overexpression were absent following LMO4 knockdown (Fig. 7B). However, overexpression of LMO4 alone was not sufficient to disrupt the basal lamina (data not shown), indicating that disruption of the basal lamina is not directly dependent on LMO4 activity.

We also analyzed components of the apical complex, including the tight junction proteins $\mathrm{ZO} 1$ and $\mathrm{aPKC}$ that line the lumen of neuroepithelial cells. Overexpression of LMO4 was insufficient to either downregulate or alter the subcellular distribution of ZO1 or aPKC (data not shown). N-cadherin is highly localized to the apical junctional region at the lumen of the NT (Fig. 8A). Delamination of NC cells involves the loss of $\mathrm{N}$-cadherin (Thiery et al., 2009; Park and Gumbiner, 2010, 2012) and overexpression of LMO4 was insufficient to alter the subcellular distribution of $\mathrm{N}$-cadherin, although the total $\mathrm{N}$-cadherin protein was reduced in a manner similar to that observed following Snail2 overexpression (Fig. 8B,C). Interestingly, LMO4 and Snail2 exhibited an additive capacity to downregulate $\mathrm{N}$-cadherin expression (Fig. $8 \mathrm{~B}, \mathrm{C}$ ), suggesting there is a functional interaction between these proteins that enhances the downregulation of cadherin expression.

\section{LMO4 and Snail 2 cooperate in repressing E- cadherin expression}

To study the LMO4/Snail2 functional interaction in a conserved repressor context, we focused on the well characterized human E-cadherin promoter, in which Snail2 binds directly to the E2 box 

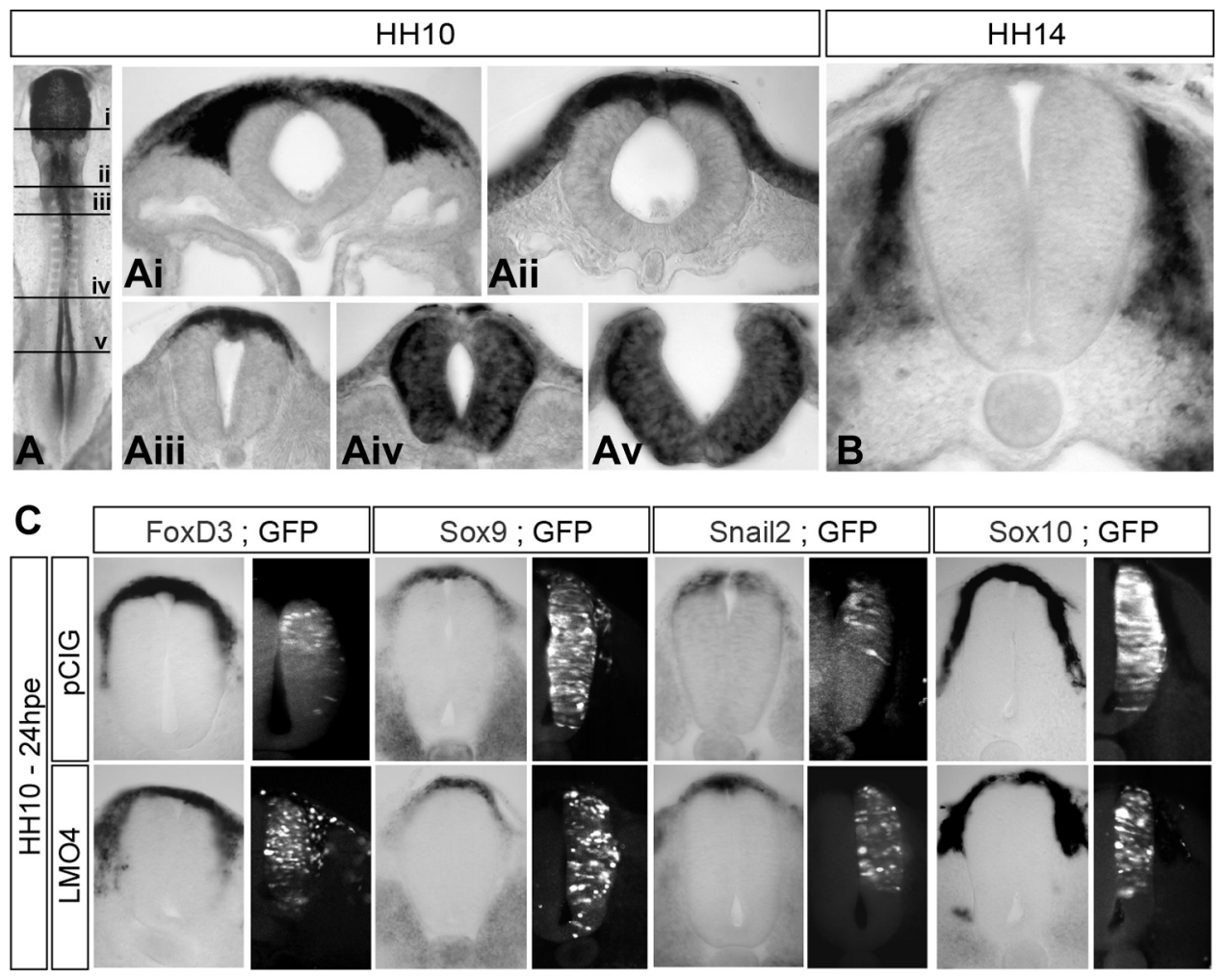

Figure 3. LMO4 is expressed in neural crest cells. In situ hybridization analysis shows LMO4 expression in chick embryos. A, At HH stage 10, LM04 was expressed in the early NT along an anterior-posterior gradient. Anterior LM04 was expressed in the dorsal NT and migratory NC in the cranial and trunk. Posterior LM04 was expressed in the open NT. B, At HH stage 14, LM04 was expressed in the migratory NC. C, LMO4 is insufficient to regulate the expression of NC genes. Expression of the indicated NC markers was analyzed in chick embryos electroporated at HH stage 10 $24 \mathrm{hpe}$, which revealed no obvious change in the expression of any NC-specific genes.
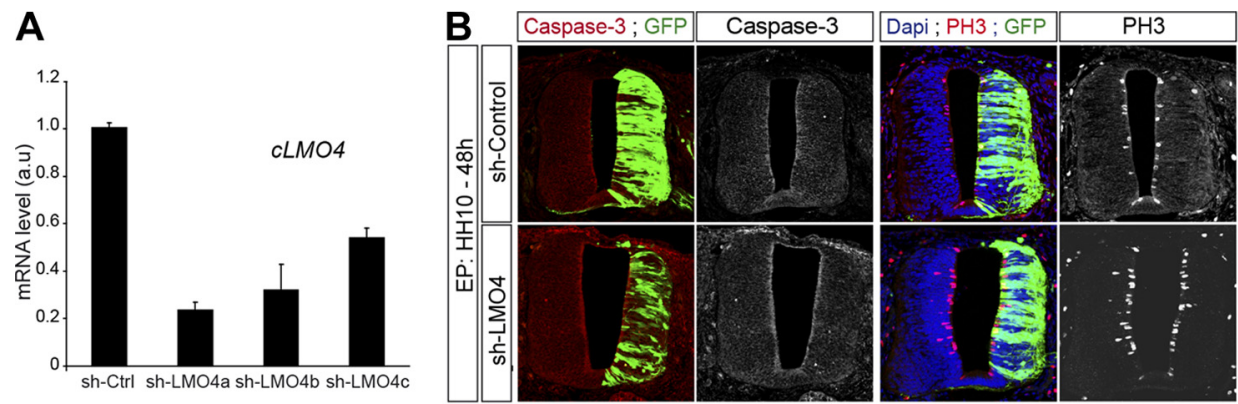

C

D
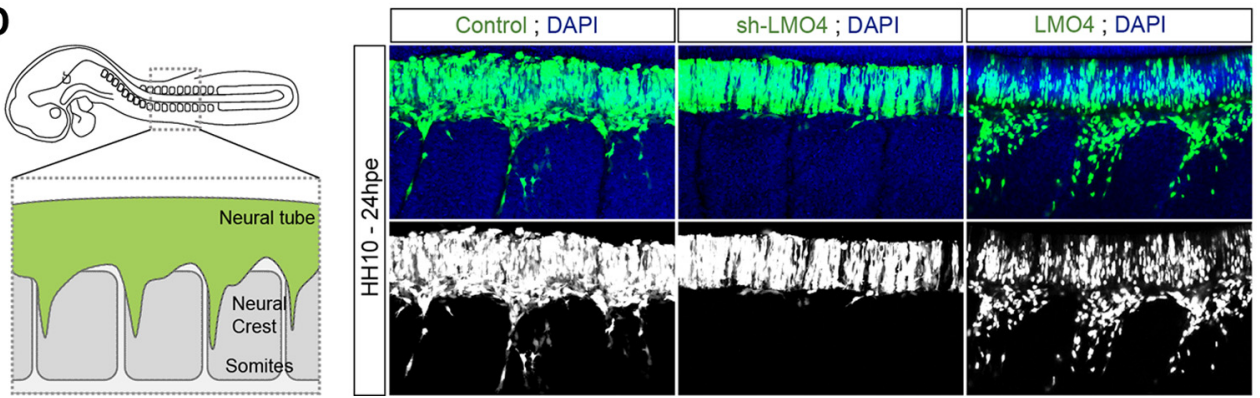

Figure 4. LMO4 controls the delamination of NC cells from the dorsal NT. A-C, Generation and characterization of chick shLM04. A, Embryos were electroporated at HH stage 12 with control shRNA or with various shLM04 constructs. Cells were harvested $36 \mathrm{~h}$ later, GFP + cells were purified by FACS, and endogenous expression of cLM04 transcripts was analyzed by RT-qPCR. On the basis of the $\sim 70 \%$ reduction in expression produced by shLM04a, this was used in all subsequent experiments. $\boldsymbol{B}$, Knockdown of LM04 did not compromise cell survival or cell proliferation, as determined by cleaved caspase-3 staining or phospho-H3 staining in control and shLMO4 electroporated embryos. C, Quantitative data show the mean \pm SEM ratios of pH3-expressing cells in the electroporated versus control nonelectroporated side of the embryos. D, Embryos electroporated at HH stage 10 with the DNAs indicated were analyzed 24 hpe for migration of GFP-expressing cells in a whole-mount preparation. Lateral view shows NC streams across three somites. 

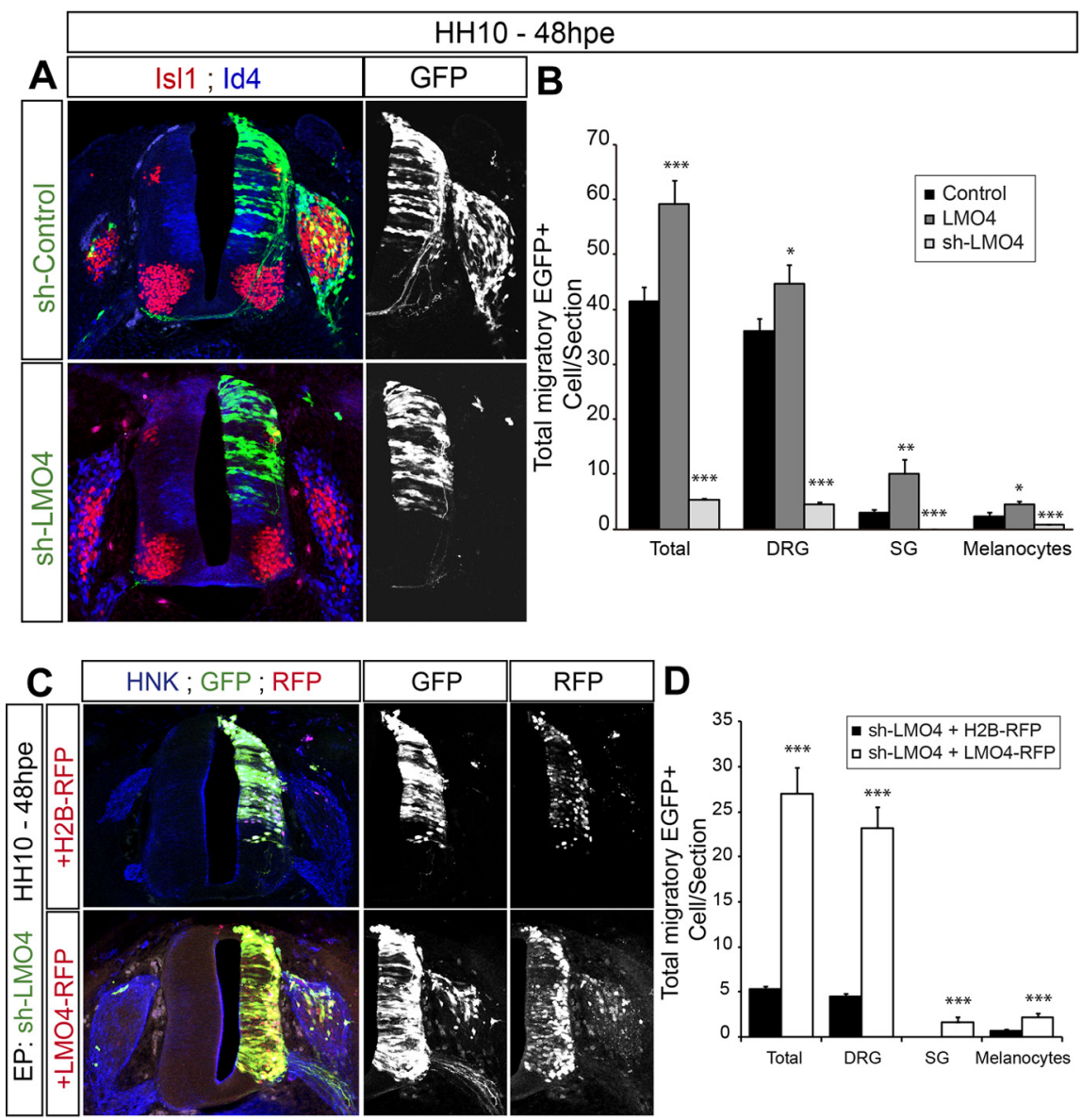

E

Total migratory EGFP+ cells/section

\begin{tabular}{|c|c|c|c|c|c|}
\hline \multicolumn{2}{|c|}{ Chick - HH10 - 48 hpe } & DRG & SG & Melanocytes \\
\hline \multirow{3}{*}{ LMO4 G.O.F } & \multirow{2}{*}{ Control } & Mean & 35,29 & 9,92 & 2,24 \\
& \multirow{2}{*}{ LMO4 } & s.e.m & 2,99 & 1,48 & 0,31 \\
\cline { 2 - 6 } & \multirow{2}{*}{ sh-Control } & Mean & 44,69 & 10,00 & 4,46 \\
& & s.e.m & 3,41 & 2,64 & 0,67 \\
\hline \multirow{3}{*}{ LMO4 L.O.F } & s.e.m & 30,86 & 12,79 & 2,05 \\
\cline { 2 - 6 } & \multirow{2}{*}{ sh-LMO4 + H2B-RFP } & Mean & 4,54 & 1,93 & 0,29 \\
\cline { 2 - 6 } & \multirow{2}{*}{ sh-LMO4 + LMO4-RFP } & s.e.m & 0,34 & 0,00 & 0,75 \\
& & sean & 23,20 & 1,65 & 0,12 \\
\hline & s.e.m & 2,41 & 0,55 & 2,15 \\
& & & & 0,49 \\
\hline
\end{tabular}

Figure 5. LM04 controls the delamination of all trunk NC derivatives. $\boldsymbol{A}$, Transverse sections (48 hpe) were analyzed for the expression of Islet1 and Id4, markers of sensory neurons. GFP-expressing cells were located in the NT and NC derivatives, including the DRG. B, Quantitative data represent the mean total \pm SEM of GFP-expressing cells in control, LM04, and shLM04 electroporated embryos, and in NC derivatives: DRG, sympathetic ganglia (SG), and melanocytes. $\boldsymbol{C}, \boldsymbol{D}$, The specificity of the shLM04 was tested by coelectroporation of human LM04 (resistant to the shRNA), which reversed the impaired NC migration. D, Quantitative data represent mean \pm SEM ratios of GFP-expressing migratory cells following shLMO4 and shLMO4 + human LMO4 coelectroporation. $\boldsymbol{E}$, Quantitative data (mean ratios or mean cell numbers \pm SEM) for indicated experiments. ${ }^{*} p<0.05$; ${ }^{* *} p<0.01$; ${ }^{* * *} p<0.001$.

to repress expression (Batlle et al., 2000). Electroporation of the human E-cadherin-Luc reporter in chick embryos revealed that although E-cadherin was not endogenously expressed in the NT, neuroepithelial cells contained sufficient endogenous transcriptional regulators to activate this reporter (Fig. $8 D, E$ ). While LMO4 or low concentrations of Snail2 alone failed to repress E-cadherin expression, coelectroporation of LMO4 and an equal concentration of Snail2 strongly repressed E-cadherin expression, supporting a role for LMO4 as a Snail2 corepressor. Interestingly, similar results were obtained when we assayed the activity of the E-cadherin reporter in $\mathrm{NB}$ cells overexpressing LMO4, Snail2, or both (Fig. $8 D, F)$.

Finally we investigated the impact of endogenous LMO4 activity on the expression of endogenous E-cadherin in NB cells. E-cadherin expression in NB cells was inversely correlated with that of LMO4 (Fig. 8G), demonstrating a clear association with the invasive capacity of these NB cells.

\section{Discussion}

In the present study, we identify LMO4 as a gene that is expressed by both neuroblastoma and NC cells. LMO4 belongs to a protein subfamily encoded by four genes (LMO1-4), and its LMO1 and LMO3 paralogues are known NB oncogenes (Aoyama et al., 2005; Isogai et al., 2011; Wang et al., 2011). We describe a novel role of LMO4 in NB, mediating tumor cell invasiveness, which is independent of any influence on the control of proliferation and/or apoptosis. Together, our results indicate that the link between high LMO4 levels and unfavorable outcomes in aggressive stage IV NBs (Yamanaka et al., 2002) is based on the regulation of cadherin expression by LMO4 and hence, on the invasiveness of these tumors. These findings might serve to design directed therapies to treat invasive neuroblastoma by reducing the level of LMO4 expression, and/or the ability of LMO4 to bind Snail2, and thus to maintain cadherin expression.

\section{LMO4 is a transcriptional modulator}

The LMO proteins (LMO1-4) contain two LIM zinc-binding domains for protein-protein interactions but they lack DNA-binding or catalytic domains. Although LMO proteins have no DNAbinding activity, a strong interaction between LMO and the nuclear LIM interactor (NLI/LDB1/CLIM2) was predicted to be responsible for negatively regulating transcription by inhibiting NLI from forming complexes with LIM-HD factors. This prediction was supported by studies in Drosophila and the vertebrate spinal cord (Milán et al., 1998; Lee et al., 2008; Joshi et al., 2009; Song et al., 2009). However, LMO4 and its binding partner NLI have been shown to interact with the basichelix-loop-helix protein Neurogenin 2 (NGN2) to form a multiprotein transcription complex, which is recruited to the E-box containing enhancers of NGN2-target genes to activate transcription (Asprer et al., 2011). These observations suggest dual roles of LMO4 in controlling the assembly of transcription factor complexes through competition with LIM factors or the recruitment of non-LIM-domain-based transcription factors. 


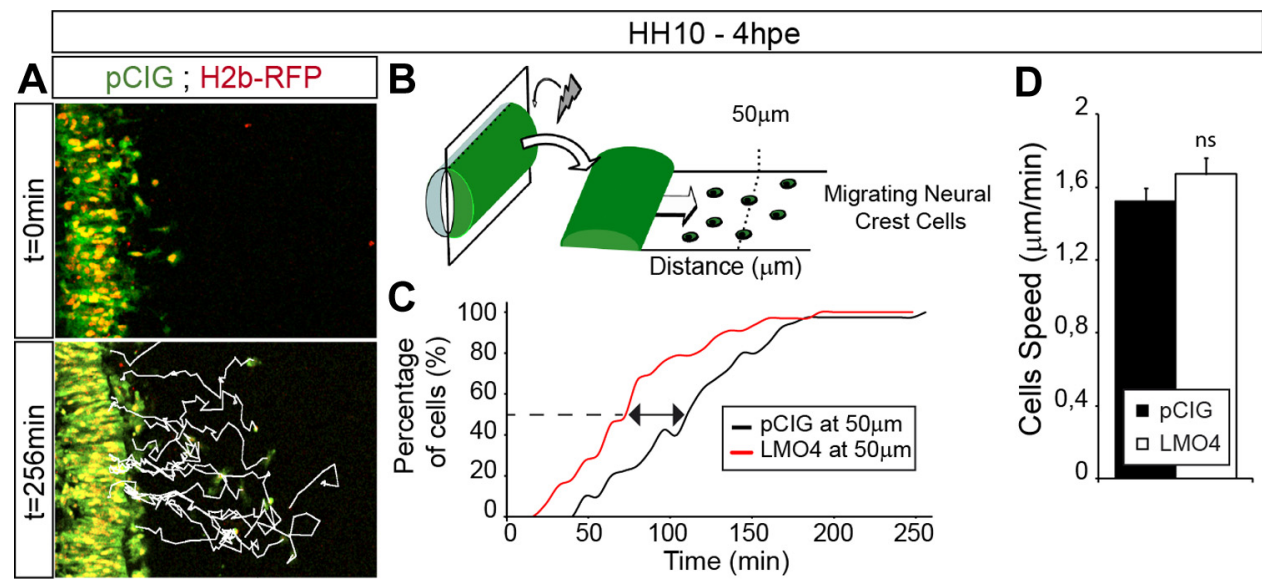

Figure 6. LM04 controls delamination of NC cells. The migratory behavior of NC cells was analyzed by time lapse in explants from control and LM04 overexpressing NTs. $A$, Representative images of the initial and final positions in control time-lapse studies. $\boldsymbol{B}$, Schematic representation of explant culture and cell tracking. $\boldsymbol{C}$, Quantitative data showed that LM04 overexpressing cells reach the $50 \mu \mathrm{m}$ milestone faster than control cells. D, Quantitative data revealed comparable speeds of migration for control and LM04 overexpressing cells.
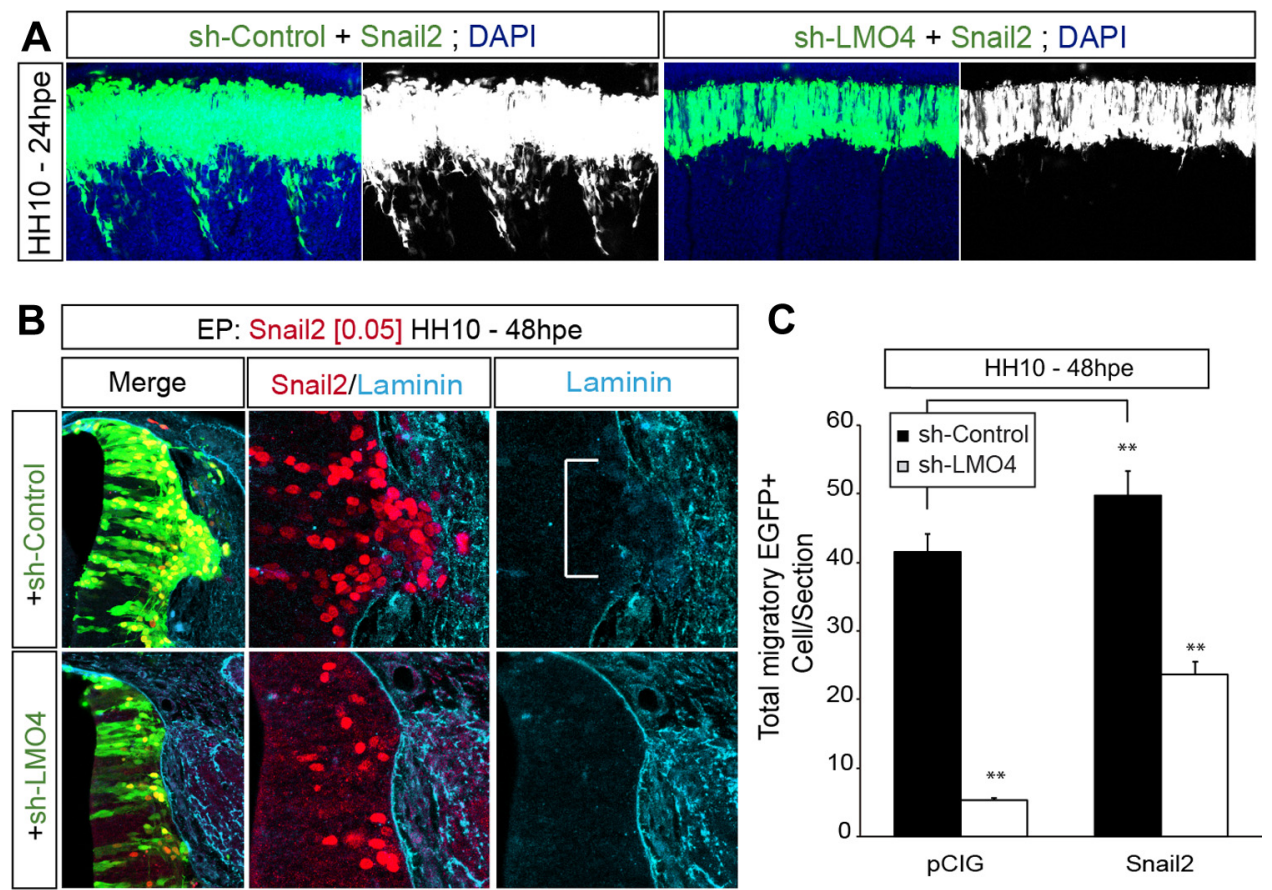

\begin{tabular}{|c|c|c|c|c|c|c|c|}
\hline \multicolumn{4}{|c|}{ Total migratory EGFP+ cells/section } & \multicolumn{4}{|c|}{ Total migratory EGFP+ cells/section } \\
\hline \multicolumn{3}{|c|}{ Chick - HH10 - 48 hpe } & Total & \multicolumn{3}{|c|}{ Chick - HH10 - 48 hpe } & Total \\
\hline \multirow{4}{*}{ LMO4 G.O.F } & \multirow{2}{*}{ Control } & Mean & 41,45 & \multirow{8}{*}{$\begin{array}{l}\text { LMO4 L.O.F } \\
\text { + Snail2 }\end{array}$} & \multirow{2}{*}{ pShin + H2B-RFP $[0.1]$} & Mean & 41,00 \\
\hline & & s.e.m & 2,71 & & & s.e.m & 3,21 \\
\hline & \multirow{2}{*}{ LMO4 } & Mean & 59,15 & & \multirow{4}{*}{ sh-LMO4 + H2B-RFP [0.1] } & Mean & 49,77 \\
\hline & & s.e.m & 4,38 & & & s.e.m & 3,66 \\
\hline \multirow{6}{*}{ LMO4 L.O.F } & \multirow{2}{*}{ sh-Control } & Mean & 47,45 & & & Mean & 5,67 \\
\hline & & s.e.m & 3,50 & & & s.e.m & 1,08 \\
\hline & \multirow{2}{*}{ sh-LMO4 + H2B-RFP } & Mean & 5,33 & & \multirow{2}{*}{ sh-LMO4 + Snail2 [0.1] } & Mean & 23,65 \\
\hline & & s.e.m & 0,36 & & & s.e.m & 1,96 \\
\hline & \multirow{2}{*}{ sh-LMO4 + LMO4-RFP } & Mean & 27,00 & & & & \\
\hline & & s.e.m & 2,87 & & & & \\
\hline
\end{tabular}

Figure 7. LM04 interacts with Snail2 to control NC delamination. $\boldsymbol{A}$, Embryos electroporated at HH stage 10 with the DNAs indicated were analyzed 24 hpe for migration of GFP-expressing cells in a whole-mount preparation. Lateral view shows NC streams across three somites. $\boldsymbol{B}$, GFP/RFP migration was analyzed at 48 hpe in embryos coelectroporated with Snail2-RFP and shRNA-GFP (control and LM04). In the absence of LM04, Snail2 was unable to disrupt the basal lamina (anti-Laminin, blue). C, Quantitative data represent the mean total \pm SEM of the total migratory control GFP and Snail2-RFP-expressing cells in shControl and shLM04 electroporated embryos $\left({ }^{* *} p<0.01\right)$. D, Quantitative data (mean ratios or mean cell numbers \pm SEM) for indicated experiments. 

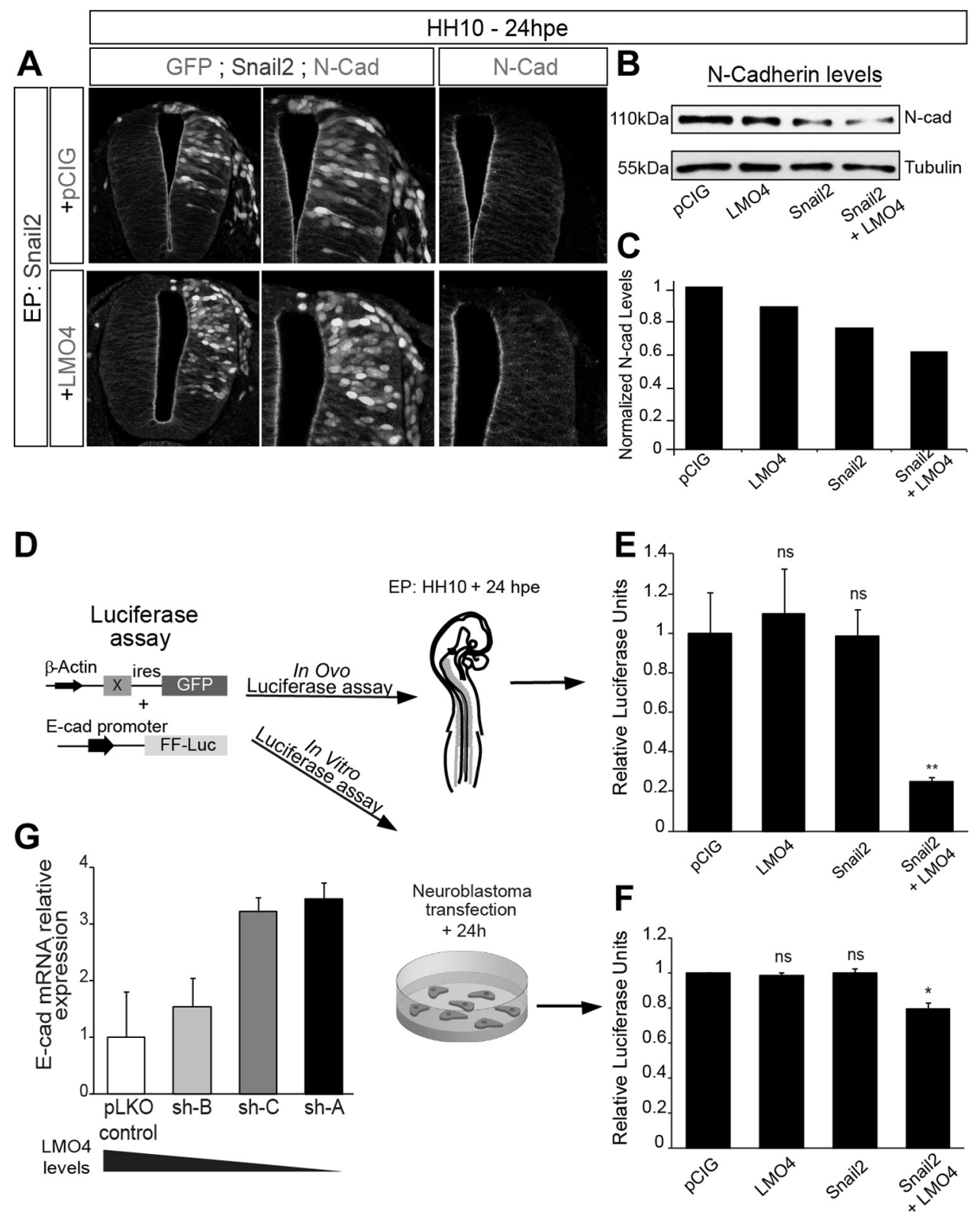

Figure 8. LM04 and Snail2 cooperate in repressing cadherin expression. A-C, N-cadherin expression (N-Cad) was analyzed 24 hpe in embryos coelectroporated with Snail2-RFP and LM04-GFP, and it was reduced on the electroporated side. $\boldsymbol{B}, \boldsymbol{C}$, In Western blots, there was a reduction in total protein levels after electroporation of Snail2 or LM04, and the additive effect of LM04 + Snail2 electroporation was evident. $\mathbf{D}-\boldsymbol{F}$, The transcriptional activity of Snail2 and LM04 was analyzed using the human E-cadherin-Luc reporter, comparing it to that of the control pCIG vector. The data demonstrate the cooperative activity of LM04 and Snail2 in repressing E-cadherin. E, Activity was tested by in ovo coelectroporation at HH stage 10 , quantifying luciferase activity at $24 \mathrm{hpe}$. $\boldsymbol{F}$, Activity was analyzed by transfection of NB cells and quantification of luciferase activity $24 \mathrm{~h}$ posttransfection. The data represent the mean \pm SEM of the relative luciferase activity expressed in arbitrary units (the mean of the control $\mathrm{pCIG}=1.0$ ). $\mathbf{G}$, Expression of E-cadherin in NB cells reveals an inverse correlation with LMO4 expression. Efficient LM04 downregulation is accompanied by an increase in E-cadherin levels. RT-qPCR results expressed as the mean \pm SD relative to the nontargeting pLK0 control shRNA. ${ }^{*} p<0.05$.

Acting as a transcriptional coactivator, $\mathrm{LMO} 4$ can interact with the MH1 and linker domains of receptor-regulated Smad proteins to coactivate the TGF- $\beta$ response in epithelial cells (Lu et al., 2006). We identified LMO4 in a genome-wide screening based on a BMP-reporter and found that LMO4 was sufficient to activate the BRE-tk-GFP reporter in the NT (data not shown). As Smad1/5 (Le Dréau et al., 2012) and Smad3 (García-Campmany and Marti, 2007) are expressed in the developing NT, we propose a model in which LMO4 enhances the transcriptional activity of endogenous Smad1/5 proteins to activate BMP-dependent responses.

\section{LMO4 is a necessary cofactor for Snail-mediated EMT}

In addition to nervous tissue, epithelial cells express high levels of LMO4, often at locations where active epithelial-to-mesenchymal interactions occur, such as the mammary gland (Sum et al., 2005; Lu et al., 2006). Furthermore, while downregulation of LMO4 expression in breast cancer cells reduces their capacity to migrate and invade the extracellular matrix, LMO4 overexpression in noninvasive, immortalized human MCF10A cells promotes their motility and invasion (Sum et al., 2005). These phenomena closely resemble the effects of LMO4 in neural cells, suggesting that the mechanisms underlying the activity of this protein are conserved in several tissues. 
Many transcription factors contribute to EMT by directly repressing surface adhesive components of epithelial cells, such as E-cadherin, claudins, and occludins. The Snail family of transcriptional repressors are central regulators of EMT in tissue morphogenesis and human pathology (Nieto, 2011). Here we demonstrate the absolute requirement of LMO4 in two models of EMT: NC and NB tumor cells. LMO4 depletion phenocopied the loss of Snail activity in the chick embryo, resulting in impaired NC delamination. Moreover, we observed clear, dose-dependent, cooperative activity of LMO4 and Snail in repressing E-cadherin expression, which may be conserved in neural cells under normal and pathological conditions. The $N$-terminal SNAG domain of Snail is required for the repression of transcription, and the LIMdomains of LMO4 bind directly to the SNAG-repressor domain of Snail (Ochoa et al., 2012). Moreover, a distant member of the LIM family of transcriptional regulators, the Ajuba-LIM protein, also binds directly to the SNAG-repressor domain of Snail and regulates E-cadherin expression (Langer et al., 2008).

However, despite the numerous studies demonstrating the essential role of the cadherin switch in NC delamination and implicating Snail in this EMT, the direct targets of Snail-mediated EMT in NC delamination remain unknown (Nakagawa and Takeichi, 1995, 1998; Taneyhill et al., 2007; Park and Gumbiner, 2010). Snail2 binding sites (E boxes) have been identified within the cadherin $6 \mathrm{~B}$ regulatory region (Taneyhill et al., 2007), however, cadherin $6 \mathrm{~B}$ activity is required for deepithelialization and disruption of the apical junction complex containing $\mathrm{N}$-cadherin in the dorsal NT (Park and Gumbiner, 2010). While Snail genes are thought to function as transcriptional repressors from Drosophila to humans (Nieto, 2002), their promotion of EMT through the direct regulation of cadherin $6 \mathrm{~B}$ would suggest an additional and novel role as transcriptional activators.

Here, we propose a model in which LMO4 acts as a required cofactor in Snail-dependent cadherin repression and EMT. It would be interesting to determine whether LMO4 proteins are also implicated in the mesenchymal-to-epithelial transition (MET). MET occurs during the morphogenesis of various organs under normal physiological and pathological conditions, such as when metastatic cells reform epithelial-like tumors at metastatic sites (Thiery et al., 2009).

\section{References}

Aoyama M, Ozaki T, Inuzuka H, Tomotsune D, Hirato J, Okamoto Y, Tokita H, Ohira M, Nakagawara A (2005) LMO3 interacts with neuronal transcription factor, HEN2, and acts as an oncogene in neuroblastoma. Cancer Res 65:4587-4597. CrossRef Medline

Asprer JS, Lee B, Wu CS, Vadakkan T, Dickinson ME, Lu HC, Lee SK (2011) LMO4 functions as a co-activator of neurogenin 2 in the developing cortex. Development 138:2823-2832. CrossRef Medline

Batlle E, Sancho E, Francí C, Domínguez D, Monfar M, Baulida J, García De Herreros A (2000) The transcription factor snail is a repressor of E-cadherin gene expression in epithelial tumour cells. Nat Cell Biol 2:84-89. CrossRef Medline

Betancur P, Bronner-Fraser M, Sauka-Spengler T (2010) Assembling neural crest regulatory circuits into a gene regulatory network. Annu Rev Cell Dev Biol 26:581-603. CrossRef Medline

Brodeur GM (2003) Neuroblastoma: biological insights into a clinical enigma. Nat Rev Cancer 3:203-216. CrossRef Medline

Cheung M, Chaboissier MC, Mynett A, Hirst E, Schedl A, Briscoe J (2005) The transcriptional control of trunk neural crest induction, survival, and delamination. Dev Cell 8:179-192. CrossRef Medline

del Barrio MG, Nieto MA (2002) Overexpression of Snail family members highlights their ability to promote chick neural crest formation. Development 129:1583-1593. Medline

De Preter K, Vandesompele J, Heimann P, Yigit N, Beckman S, Schramm A, Eggert A, Stallings RL, Benoit Y, Renard M, De Paepe A, Laureys G,
Påhlman S, Speleman F (2006) Human fetal neuroblast and neuroblastoma transcriptome analysis confirms neuroblast origin and highlights neuroblastoma candidate genes. Genome Biol 7:R84. CrossRef Medline

Duband JL, Blavet C, Jarov A, Fournier-Thibault C (2009) Spatio-temporal control of neural epithelial cell migration and epithelium-tomesenchyme transition during avian neural tube development. Dev Growth Differ 51:25-44. CrossRef Medline

García-Campmany L, Martí E (2007) The TGFbeta intracellular effector Smad3 regulates neuronal differentiation and cell fate specification in the developing spinal cord. Development 134:65-75. CrossRef Medline

Hahm K, Sum EY, Fujiwara Y, Lindeman GJ, Visvader JE, Orkin SH (2004) Defective neural tube closure and anteroposterior patterning in mice lacking the LIM protein LMO4 or its interacting partner Deaf-1. Mol Cell Biol 24:2074-2082. CrossRef Medline

Isogai E, Ohira M, Ozaki T, Oba S, Nakamura Y, Nakagawara A (2011) Oncogenic LMO3 collaborates with HEN2 to enhance neuroblastoma cell growth through transactivation of Mash1. PLoS One 6:e19297. CrossRef Medline

Jiang M, Stanke J, Lahti JM (2011) The connections between neural crest development and neuroblastoma. Curr Top Dev Biol 94:77-127. CrossRef Medline

Joshi K, Lee S, Lee B, Lee JW, Lee SK (2009) LMO4 controls the balance between excitatory and inhibitory spinal V2 interneurons. Neuron 61: 839-851. CrossRef Medline

Langer EM, Feng Y, Zhaoyuan H, Rauscher FJ 3rd, Kroll KL, Longmore GD (2008) Ajuba LIM proteins are snail/slug corepressors required for neural crest development in Xenopus. Dev Cell 14:424-436. CrossRef Medline

Le Dréau G, Garcia-Campmany L, Rabadán MA, Ferronha T, Tozer S, Briscoe J, Martí E (2012) Canonical BMP7 activity is required for the generation of discrete neuronal populations in the dorsal spinal cord. Development 139:259-268. CrossRef Medline

Lee SK, Jurata LW, Nowak R, Lettieri K, Kenny DA, Pfaff SL, Gill GN (2005) The LIM domain-only protein LMO4 is required for neural tube closure. Mol Cell Neurosci 28:205-214. CrossRef Medline

Lee S, Lee B, Joshi K, Pfaff SL, Lee JW, Lee SK (2008) A regulatory network to segregate the identity of neuronal subtypes. Dev Cell 14:877-889. CrossRef Medline

Lu Z, Lam KS, Wang N, Xu X, Cortes M, Andersen B (2006) LMO4 can interact with Smad proteins and modulate transforming growth factorbeta signaling in epithelial cells. Oncogene 25:2920-2930. CrossRef Medline

Maris JM, Hogarty MD, Bagatell R, Cohn SL (2007) Neuroblastoma. Lancet 369:2106-2120. CrossRef Medline

Milán M, Diaz-Benjumea FJ, Cohen SM (1998) Beadex encodes an LMO protein that regulates Apterous LIM-homeodomain activity in Drosophila wing development: a model for LMO oncogene function. Genes Dev 12:2912-2920. CrossRef Medline

Morales AV, Acloque H, Ocaña OH, de Frutos CA, Gold V, Nieto MA (2007) Snail genes at the crossroads of symmetric and asymmetric processes in the developing mesoderm. EMBO Rep 8:104-109. CrossRef Medline

Nakagawa S, Takeichi M (1995) Neural crest cell-cell adhesion controlled by sequential and subpopulation-specific expression of novel cadherins. Development 121:1321-1332. Medline

Nakagawa S, Takeichi M (1998) Neural crest emigration from the neural tube depends on regulated cadherin expression. Development 125:29632971. Medline

Nieto MA (2002) The Snail superfamily of zinc-finger transcription factors. Nat Rev Mol Cell Biol 3:155-166. CrossRef Medline

Nieto MA (2011) The ins and outs of the epithelial to mesenchymal transition in health and disease. Annu Rev Cell Dev Biol 27:347-376. CrossRef Medline

Ochoa SD, Salvador S, LaBonne C (2012) The LIM adaptor protein LMO4 is an essential regulator of neural crest development. Dev Biol 361:313-325. CrossRef Medline

Park KS, Gumbiner BM (2010) Cadherin 6B induces BMP signaling and de-epithelialization during the epithelial mesenchymal transition of the neural crest. Development 137:2691-2701. CrossRef Medline

Park KS, Gumbiner BM (2012) Cadherin-6B stimulates an epithelial mesenchymal transition and the delamination of cells from the neural ectoderm via LIMK/cofilin mediated non-canonical BMP receptor signaling. Dev Biol 366:232-243. CrossRef Medline 
Schramm A, von Schuetz V, Christiansen H, Havers W, Papoutsi M, Wilting J, Schweigerer L (2005) High activin A-expression in human neuroblastoma: suppression of malignant potential and correlation with favourable clinical outcome. Oncogene 24:680-687. CrossRef Medline

Schulte JH, Schramm A, Klein-Hitpass L, Klenk M, Wessels H, Hauffa BP, Eils J, Eils R, Brodeur GM, Schweigerer L, Havers W, Eggert A (2005) Microarray analysis reveals differential gene expression patterns and regulation of single target genes contributing to the opposing phenotype of TrkA- and TrkB-expressing neuroblastomas. Oncogene 24:165-177. CrossRef Medline

Song MR, Sun Y, Bryson A, Gill GN, Evans SM, Pfaff SL (2009) Islet-toLMO stoichiometries control the function of transcription complexes that specify motor neuron and V2a interneuron identity. Development 136:2923-2932. CrossRef Medline

Sum EY, Segara D, Duscio B, Bath ML, Field AS, Sutherland RL, Lindeman GJ, Visvader JE (2005) Overexpression of LMO4 induces mammary hyperplasia, promotes cell invasion, and is a predictor of poor outcome in breast cancer. Proc Natl Acad Sci U S A 102:7659-7664. CrossRef Medline

Taneyhill LA, Coles EG, Bronner-Fraser M (2007) Snail2 directly represses cadherin6B during epithelial-to-mesenchymal transitions of the neural crest. Development 134:1481-1490. CrossRef Medline
Theveneau E, Mayor R (2012) Neural crest delamination and migration: from epithelium-to-mesenchyme transition to collective cell migration. Dev Biol 366:34-54. CrossRef Medline

Thiery JP, Acloque H, Huang RY, Nieto MA (2009) Epithelialmesenchymal transitions in development and disease. Cell 139:871890. CrossRef Medline

Tse E, Smith AJ, Hunt S, Lavenir I, Forster A, Warren AJ, Grutz G, Foroni L, Carlton MB, Colledge WH, Boehm T, Rabbitts TH (2004) Null mutation of the Lmo4 gene or a combined null mutation of the Lmo1/Lmo3 genes causes perinatal lethality, and Lmo4 controls neural tube development in mice. Mol Cell Biol 24:2063-2073. CrossRef Medline

Wang K, Diskin SJ, Zhang H, Attiyeh EF, Winter C, Hou C, Schnepp RW, Diamond M, Bosse K, Mayes PA, Glessner J, Kim C, Frackelton E, Garris M, Wang Q, Glaberson W, Chiavacci R, Nguyen L, Jagannathan J, Saeki $\mathrm{N}$, et al. (2011) Integrative genomics identifies LMO1 as a neuroblastoma oncogene. Nature 469:216-220. CrossRef Medline

Yamanaka Y, Hamazaki Y, Sato Y, Ito K, Watanabe K, Heike T, Nakahata T, Nakamura Y (2002) Maturational sequence of neuroblastoma revealed by molecular analysis on cDNA microarrays. Int J Oncol 21:803-807. Medline 